\title{
TECNOLOGIA E PARTICIPAÇÃO SOCIAL NO PROCESSO DE PRODUÇÃO E CONSUMO DE BENS CULTURAIS: NOVAS POSSIBILIDADES TRAZIDAS PELAS PRÁTICAS LETRADAS DIGITAIS MEDIADAS PELA INTERNET
}

\author{
TECHNOLOGY AND SOCIAL PARTICIPATION IN THE PROCESS OF \\ PRODUCTION AND CONSUMPTION OF CULTURAL GOODS: NEW \\ OPPORTUNITIES OFFERED BY DIGITAL LITERACY PRACTICES \\ MEDIATED BY THE INTERNET
}

\author{
DENISE BÉRTOLI BRAGA*
}

\begin{abstract}
RESUMO: O presente artigo reflete sobre os limites sócio-estruturais que impedem a participação social mais ampla dos grupos economicamente desfavorecidos. O texto argumenta que, embora a Internet não garanta tal participação, ela propicia novos espaços para circulação social em práticas letradas diversas, inclusive aquelas de natureza hegemônica. Para ilustrar essa questão o artigo discute dados de uma entrevista realizada com um jovem líder que atua em uma comunidade localizada na periferia da cidade de Campinas, São Paulo. Os argumentos e colocações apresentados pelo entrevistado nos levam a refletir sobre a democratização dos modos de produção e consumo do conhecimento, em geral, e sobre a possibilidade de apropriação das TICs por comunidades periféricas, em particular.

Palavras chaves: Internet; participação social; apropriação local das TICs; letramentos digitais.
\end{abstract}

\begin{abstract}
The present paper focuses on the limits socio-structurally imposed to exclude the social participation of economically disadvantaged groups in different spheres of cultural production and consumption. The paper argues that, although not guaranteeing new modes of participation, the Internet offers new virtual spaces that broaden the access to diversified ways of social circulation and participation in digital literacy practices, including those hegemonic in nature. To illustrate some of these major issues the study focuses on the data of an interview given by a young leader from a peripheral community located on the outskirts of the city of Campinas, São Paulo. The statements and arguments presented by the interviewee lead us to reflect on the process of democratization of knowledge production and consumption, in general, and about ICT appropriation by peripheral communities, in particular.
\end{abstract}

Palavras chaves: Inte

Keywords: Internet; social participation; local appropriation of ICT resources; digital literacies.

\section{INTRODUÇÃO}

As relações de poder na sociedade mais ampla afetam de modo bastante direto as formas de ordenamento e representação social - uma questão que vem sendo muito debatida, tanto nas teorias políticas de perspectiva marxista e neo-marxista (GIDDENS, 1987), quanto

\footnotetext{
*Unicamp, Campinas (SP), Brasil. <denisebbraga@gmail.com>
} 
BRAGA — Tecnologia e participação social no processo de produção...

nas teorias mais voltadas para as construções discursivas, como as desenvolvidas nos estudos de Michael Foucault. Para Giddens os recursos do poder, autoridade e estrutura de dominação política exercem um papel crucial nos sistemas de produção e reprodução social. Na visão do autor, como bem sintetiza Jessop, 1989, todo processo de estruturação social envolve três elementos: a comunicação de sentido, o exercício do poder e o julgamento qualitativo da conduta. Esses elementos têm implicações tanto para a constituição da estrutura social, quanto para os espaços de agentividade dentro da estrutura criada, já que delineiam: no nível da significação, as normas de construção de sentidos; no nível da dominação, a distribuição desigual de recursos; e no nível da legitimação, a determinação das regras morais e de avaliação social.

O avanço no desenvolvimento das tecnologias de informação e comunicação (TICs) não garante a subversão desses modos de estruturação social. No entanto, o aumento e a diminuição de custos envolvidos no acesso à informação e à interação a distância viabilizados pela Internet ampliam, ou mesmo criam, novos espaços para a participação social, os quais carregam em si um potencial transformador. Como prevê a reflexão gramsciana, embora as restrições sócio-estruturais estabeleçam limites para a ação social, a malha social é constituída de brechas, rupturas e conflitos que viabilizam agentividade e potencializam mudanças sociais. A extensão e gradação de tais mudanças vai certamente variar de acordo com o poder de coesão e de exclusão social exercido pelos grupos hegemônicos e também de acordo com a capacidade de organização e de ação política dos grupos não-hegemônicos. Em função da natureza de tais ações, esses grupos podem ou não ocupar e ampliar as brechas já existentes de modo a gerar mudanças locais ou rupturas mais radicais (GRAMSCI, 1971).

A apropriação social dos recursos oferecidos pelas TICs ilustra bem a forma como as mudanças sociais tendem a ser complexas e a gerar resultados inicialmente não previstos. É possível afirmar, por exemplo, que os avanços obtidos no campo das TICs foram, em grande parte, financiados pelos grupos que ocupam as esferas do poder econômico, os quais passaram a ver o processo de globalização do mercado e da cultura como uma oportunidade promissora para ampliar negócios dentro da perspectiva ditada pelo modelo do novo capitalismo. Assim, os recursos que tornaram a comunicação a distância e os modos de consulta online rápidos e eficientes, passaram a ser incorporados à "nova ordem de trabalho" (GEE, 1991). As novas demandas do mundo empresarial acabaram incentivando o investimento no desenvolvimento das tecnologias de comunicação o que, por um lado, gerou uma sofisticação sem precedentes desses recursos técnicos e, por outro lado, promoveu uma queda nos custos que permitiu a apropriação dessa tecnologia pelas diversas camadas da população. Como é previsível, a ampliação do uso das TICs nas situações cotidianas e de trabalho gerou diferentes apropriações e usos das práticas letradas digitais, tanto por parte dos grupos hegemônicos, quanto por parte das comunidades periféricas. Em síntese, é possível dizer que as novas tecnologias paradoxalmente servem a propósitos sociais antagônicos: de um lado elas viabilizam uma concentração de poder no nível global sem precedentes; do outro lado elas potencializam, no nível local, o acesso dos grupos socialmente desfavorecidos à informação e ao contato social fora dos limites geográficos das comunidades e grupos de origem, permitindo modos de participação social mais democráticos.

Refletindo mais cuidadosamente sobre esse último ponto, é fato que a distribuição desigual de recursos materiais e as barreiras levantadas para o acesso à informação em 
certos contextos sociais de prestígio historicamente sempre favoreceram os grupos economicamente privilegiados. A falta do domínio da "língua correta", da "aparência correta", do "comportamento correto" entre outros, sempre foram argumentos explorados para impedir a participação ou justificar a exclusão de indivíduos oriundos de outros grupos sociais. Além disso, é fato que a falta de recursos financeiros coloca sérias barreiras para a participação real das camadas economicamente desfavorecidas no processo de socialização nos bens culturais de prestígio como aqueles veiculados através de material impresso, cinema, teatro, entre outros. Mais recentemente, essa diferença social também pode ser constatada de forma bem evidente em relação aos programas televisivos: se antes os canais abertos da televisão brasileira destinavam-se a uma audiência constituída de todos os grupos sociais, a chegada dos canais pagos gerou um deslocamento da classe média e média alta para essa nova opção. Essa mudança, na medida em que afeta de forma direta a natureza e a qualidade dos programas oferecidos na rede aberta de televisão, expõe o fato de que a participação das diferentes camadas sociais da população brasileira nos processos de consumo e produção cultural sempre foi e ainda é bastante desigual. A tecnologia da Internet não muda de forma drástica esse panorama. Ter um computador residencial conectado à Internet ainda não é um privilégio estendido a toda a população. Mesmo considerando esse limite, é fato que com a expansão das lan-houses, dos centros comunitários que oferecem acesso a laboratórios de informática, ou do uso coletivo que é feito da tecnologia nas comunidades carentes, existe atualmente um espaço potencial de participação e circulação social que há dez anos não poderia ser contemplado.

Nessa direção, mesmo sem assumir uma posição excessivamente otimista, o presente artigo tem por meta discutir as novas formas de construção de sentidos trazidas pela Internet. Entender tais construções pode ser um primeiro passo para educadores progressistas conceberem formas de explorar as possibilidades oferecidas pelas novas tecnologias de modo a ampliar o escopo da participação social de todos os grupos e, em especial, a participação social das comunidades economicamente desfavorecidas. Essas podem usar tais recursos como uma forma de contornar barreiras historicamente sedimentadas e que impedem o acesso a bens culturais. Pensar em formas de apropriação crítica é uma questão fundamental. Nas palavras de Braga:

(...) a tecnologia, como qualquer produto social não é neutra: sua criação ou adoção por comunidades específicas é guiada por interpretações sobre o potencial que elas tem para satisfazer necessidades sociais específicas. Em outras palavras, a direção do desenvolvimento tecnológico e das mudanças sociais dele advindas está sempre ligada à valores e ideologias culturais pré-existentes que podem também mudar em novas direções quando a adoção dessa tecnologia transforma a própria natureza das práticas sociais pré-existentes (BRAGA, 2007c:80).

\section{CIRCULAÇÃo SOCIAL, PARTICIPAÇÃo EM PRÁtiCAS DISCURSIVAS INSTITUCIONAIS}

Em estudos que se tornaram referência nos debates iniciais sobre letramentos, desenvolvidos nos anos ' 80 por Heath, 1983 e Michaels e Collins, 1984, ficou evidente que as práticas interativas familiares, atreladas a uma maior ou menor mediação da escrita, 
BRAGA - Tecnologia e participação social no processo de produção...

geram esquemas interpretativos que podem ter efeitos nos modos de produção e recepção de textos. Essas novas formas de interpretação podem explicar um conjunto de conflitos comunicativos em práticas escolares que envolvem a participação conjunta de indivíduos oriundos de grupos socioculturais distintos. Conflitos mais amplos foram discutidos em detalhes na pesquisa de cunho etnográfico desenvolvida por Heath, a qual ilustra como um grupo de classe média americana e dois grupos de classe econômica trabalhadora são privilegiados ou excluídos em diferentes etapas da escolarização, dada a natureza das práticas comunicativas e experiência letrada que constituem sua bagagem cultural comunitária.

O estudo de Michael e Collins aprofunda a reflexão sobre tais diferenças trazendo dados empíricos que ilustram, através de uma análise linguística detalhada, alguns conflitos comunicativos que ocorrem dentro de uma prática escolar específica - o ato de narrar histórias - realizada no período de pré-alfabetização. Contrastando a produção de narrativas de crianças brancas de classe média com a de crianças negras americanas, os autores constataram que as crianças brancas tendiam a adotar um estilo discursivo centrado em um tópico explícito denominado, nesse estudo, estilo discursivo centrado no tópico. $\mathrm{Na}$ progressão da narrativa dessas crianças, as mudanças entre temas e subtemas eram lexicalmente sinalizadas (um padrão mais próximo daquele adotado em narrativas escritas), e os recursos prosódicos eram utilizados para marcar as seguintes funções: estabelecer cena ou perspectiva, elaborar mais o tópico, ou fechamento de tópico. Já as crianças negras investigadas adotavam o estilo denominado pelos autores associação de tópicos: além de o tema geral do eixo narrativo ser deixado implícito, os recursos prosódicos são explorados para marcar o limite entre temas e subtemas. Desconhecendo as normas discursivas adotadas pelas crianças negras, a professora ficava com a impressão de que elas apenas relatavam um conjunto de episódios aleatoriamente associados, fugindo do proposto pela tarefa escolar: falar sobre só "um assunto". Os conflitos comunicativos detectados entre essas crianças e a professora foram, nesse estudo, explicados em termos de normas linguísticas não compartilhadas (no caso de usos específicos de traços prosódicos e ausência de marcas lexicais indicando mudanças no foco temático) e do conceito de inferência conversacional proposto por Gumperz , 1977. Esse conceito abarca diferentes níveis de pistas de sentido - verbais e não verbais - e todos os níveis do discurso. Tais inferências ocorrem em processos de interpretação situados, por meio dos quais os participantes de uma conversação acessam a intenção comunicativa do seu interlocutor e respondem com base nesse acesso. Diferentes normas e expectativas conversacionais geram conflitos e diferenças no processo de interpretação mútua.

As pesquisas que seguiram a orientação etnográfica adotada no estudo de Heath, assim como no de Michael e Collins, foram muito importantes para contestar interpretações das diferenças socioculturais a partir de noções preconceituosas, que tendiam, na literatura da época, a rotular o "diferente" como sendo "primitivo", "simples" e, em última instância, "qualitativamente inferior". Pode-se afirmar que a valorização do multiculturalismo foi um avanço teórico importante trazido pelos estudos sobre o letramento. No entanto, a discussão sobre o respeito à diferença e à diversidade cultural nem sempre foi associado a reflexões socioestruturais mais amplas, necessárias para o questionamento sobre o acesso diferenciado aos bens culturais, que caracteriza diferentes grupos comunitários - as possibilidades de escolha e participação não são igualmente distribuídas. 
Revisitando os dados das narrativas das crianças negras estudadas por Michael e Collins é possível, por exemplo, retomar e expandir as questões relativas à inferência conversacional, para construir uma hipótese que justifique a falta de explicitação do tópico central da narrativa encontrada nos resultados do estudo. Essa outra explicação incluiria questões de acesso e circulação social, considerando que, nas camadas sociais economicamente carentes o contato com práticas discursivas tende a ficar mais restrito aos limites familiares e comunitários próximos. Tal proximidade amplia o escopo do conhecimento compartilhado, o que permite a omissão de muitas informações passíveis de serem inferidas pelo interlocutor tendo como base o conhecimento mútuo pressuposto. Ou seja, a proximidade e a familiaridade cultural viabilizam a inferência do tópico e uma série de outras inferências de cunho linguístico-pragmático, o que explicaria o apagamento de tais informações nas narrativas analisadas. É possível, assim, prever que as crianças de classe média têm também, além de um contato diferenciado com textos escritos, mais oportunidades de contatos sociais diversificados fora de seu convívio familiar mais imediato. Essa talvez seja uma forma plausível de re-interpretar a natureza dos padrões descritos no estudo de Michael e Collins.

Para fins do presente estudo, essa retomada de uma pesquisa bastante citada nas reflexões sobre letramentos desenvolvidas nas décadas de '80 e '90 visa instigar a construção de uma nova questão relacionada agora a novos tipos de letramentos que surgiram no meio digital. Mais especificamente, a nova questão que se coloca é: em que medida o desenvolvimento das tecnologias de informação e comunicação, principalmente da Internet, ao transformarem as relações de espaço e tempo, ao tornarem a comunicação a distância mais ágil e economicamente viável e, finalmente, ao permitirem a integração de múltiplas semioses ampliam o espaço de acesso e circulação social dos grupos economicamente desfavorecidos?

De um modo geral, é possível conjecturar que o espaço virtual possa favorecer a democratização da cultura de diferentes maneiras. É possível, por exemplo, o indivíduo ter acesso rápido à informação, antes dificultado por questões de tempo e espaço - como as consultas às bibliotecas, por exemplo - ou pelo custo elevado da aquisição de reproduções impressas. No caso do material impresso, o uso do dialeto padrão na modalidade escrita sempre foi uma séria barreira para o acesso a bens culturais de prestígio (GNERRE, 1991): a aquisição de discursos e gêneros formais tende a ter uma forte vinculação a níveis de escolarização mais avançados das instituições que atendem uma clientela economicamente privilegiada. Entretanto, mesmo considerando essas possíveis vantagens, talvez a contribuição mais importante da Internet, em termos de democratização da cultura, seja o fato de a tecnologia digital ter permitido que todos os grupos sociais - dominando os recursos técnicos necessários - pudessem ser produtores de textos destinados a uma audiência ampla, um processo antes controlado pelos custos de reprodução, possibilidade de distribuição e políticas editoriais. Abriu-se de fato um espaço singular para o acesso público à multiplicidade das vozes sociais que constituem a sociedade mais ampla.

Em termos de circulação e participação social, as comunidades virtuais, além de aproximarem grupos com interesses comuns, ampliaram os espaços de participação de duas formas distintas. Primeiro, elas permitem que indivíduos que não pertencem a determinados grupos sejam expostos a gêneros e discursos adotados por esses grupos, 
dando lugar a aproximações e apropriações gradativas de tais gêneros e discursos. Em segundo lugar, elas permitem que barreiras normalmente levantadas por fatores como gênero, raça, idade, aparência física, classe socioeconômica sejam "ocultados" no ambiente virtual, possibilitando um maior contato e até interação entre diferenças sociais. A legitimação da participação, nesse caso, deixa de ser determinada pelo acesso ao espaço geográfico em que determinados grupos se reúnem nas comunidades tradicionais, e pela avaliação de fatores externos, um recurso que tende a ser explorado para impedir ou desqualificar as contribuições de membros considerados "externos" ao grupo.

Tendo como referência o estudo de Certeau, 1994, Buzato, 2007 e 2008, defende que a forma de apropriação dos letramentos digitais no cotidiano dos sujeitos subalternos não deve ser entendida como simples reprodução de - ou "inclusão" em - padrões de letramentos pré-estabelecidos:

\footnotetext{
O usuário da linguagem digital e de dispositivos digitais (...) como qualquer leitor não é um mero consumidor. Ele pratica essa linguagem e esses dispositivos, lança mão daquilo que Certeau (1994) chama de usos e táticas para apropriar-se do que lhe é dado a ler (em sentido mais amplo) de maneiras peculiares, por vezes transgressivas, irônicas ou políticas. Ao fazê-lo, entretanto, ele lança mão de scripts, recursos interativos e modelos interpretativos, culturalmente compartilhados aos quais chamamos de letramento. (BUZATO, 2008: 327-328)
}

Os dados analisados por Buzato (opus cit.) ilustram essa possibilidade ressaltando alguns usos criativos e mesmo transformadores do letramento digital. Um dos exemplos mencionados pelo autor é o caso do indivíduo que explora os recursos da rede para, estrategicamente, encontrar caminhos para a realização de um sonho profissional: ser um jogador profissional de futebol em um time de prestígio. A pesquisa de Buzato oferece um conjunto de outros exemplos de uso das TICs que indicam que a apropriação local dos letramentos digitais pode ser tanto criativa, inovadora e expandir universo referencial e participativo dos indivíduos incluídos na periferia social, quanto servir a funções locais e familiares, que poderiam ser realizadas fora do âmbito digital como, por exemplo, usar o MSN para conversar com pessoas que se encontram presentes no mesmo laboratório de informática, ou buscar estabelecer novas interações sociais dentro dos limites geográficos da própria comunidade. Práticas sociais novas e também as mais familiares parecem competir nos modos de apropriação local do letramento digital. Deslocando o foco da presente discussão para a participação dos grupos socialmente desfavorecidos - não só nas esferas locais, mas também nas esferas de prestígio e poder social -, interessa-nos refletir sobre as possibilidades que a Internet abre para uma participação mais democrática nos modos de consumo e produção da cultura mais ampla. Nesse sentido, as diretrizes que inspiraram o movimento em prol da produção de software livre podem ser consideradas um espaço privilegiado para nos instigar a tal reflexão.

\section{HEGEMONIA E PRODUÇÃO DE CONHECIMENTO NO CONTEXTO E GLOBALIZAÇÃODOMERCADOEDACULTURA}

O desenvolvimento das TICs foi simultaneamente propiciado e demandado por um estágio do capitalismo moderno caracterizado por uma "desterritorialização" dos grupos 
hegemônicos (Bauman, 2001 e 2003). Essa nova estrutura, que se ancora no aperfeiçoamento das tecnologias de comunicação, confere um lugar de poder privilegiado para programadores, já que no meio digital a interação entre indivíduo/máquina ou entre indivíduo/indivíduos depende diretamente das possibilidades oferecidas pelas ferramentas técnicas existentes. Como sugere Braga:

(...) no contexto da linguagem das novas mídias, os programadores que atuam na área da computação tornaram-se uma elite poderosa, cuja perspectiva e escolhas formatam a natureza dos códigos e convenções que são integrais ao processo do uso do computador e da rede em geral. (BRAGA, 2007c: 81)

Sendo assim, como reflete a autora, esse é um campo privilegiado para refletirmos sobre processos de reprodução e transformação já previstos no conceito gramsciano de hegemonia. Para Gramsci, a hegemonia cultural se instaura não só através da violência e coerção econômica e política, mas também através da criação de um consenso social que prioriza determinadas ideologias em detrimento de outras. No entanto, a criação e manutenção desse consenso, através do qual o "senso comum" das classes desfavorecidas se identifica com modelos sociais que servem aos interesses dos grupos dominantes, não ocorre de forma pacífica. Há sempre conflitos a serem contornados, gerados por divergências que ocorrem entre grupos sociais e também dentro de um mesmo grupo social. Na visão gramsciana, a estrutura social é constituída por brechas e rupturas dentro das quais os conflitos tanto são combatidos, desqualificados ou mesmo reprimidos nos movimentos de reprodução das ideologias hegemônicas, quanto são explorados para informar e incentivar movimentos de ação social que geram resistência e lutas em direções contra-hegemônicas. O debate que se construiu em torno da criação de softwares ilustra duas direções distintas adotadas por grupos que passaram a defender modos mais colaborativos de trabalho e a contestar a forma tradicional e hierárquica de construção dessas ferramentas. No entanto, apesar de criticarem a política de desenvolvimento de software adotada pelas empresas tradicionais no mercado, ambos os movimentos adotam perspectivas ideológicas diferenciadas: uma de cunho anarquista, orientada pelo conceito de democratização do conhecimento técnico; a outra norteada pelo discurso da qualidade técnica (uma nova forma de produção que coloca produtos inacabados para testes nas comunidades virtuais) e da possibilidade de novas oportunidades para criação de negócios na área técnica esses não mais vinculados à política de produção das grandes empresas existentes, como a Microsoft Corporation.

Discutindo essas diferenças em mais detalhes, a primeira tendência, conhecida como o movimento do software livre, surgiu de um princípio revolucionário que defendia o direito humano à liberdade e à escolha (POYNDER, 2007). Essa iniciativa, liderada por Richard Stallman, foi a princípio motivada por um conflito de interesse. Stallman queria programar uma impressora central para atender as necessidades específicas de seu grupo de pesquisa no MIT e teve sua iniciativa impedida por não ter acesso ao código fonte da impressora, considerado propriedade da Xerox Corporation. Tal conflito levou o pesquisador a iniciar um movimento ancorado no seguinte principio ético: compartilhar informações é um ato necessário para a cooperação humana e, portanto, a recusa de compartilhar um determinado código fonte é um ato socialmente hostil. Essa questão foi, posteriormente, 
BRAGA — Tecnologia e participação social no processo de produção...

acirrada, ainda no início dos anos '80, quando o MIT licenciou um programa que estava desenvolvendo (LISP System) no nome de duas companhias. Umas dessas companhias Symbolics - declarou que negava a permissão do MIT de copiar o programa em seu próprio sistema ou realizar mudanças ou melhorias nos programas desenvolvidos pela Symbolics. Como um movimento de rebelião contra essa decisão, Stallman iniciou uma campanha incentivando ações de "hacking" nos softwares produzidos pela Symbolic. Quanto tais ações foram bloqueadas através de uma mudança de máquinas no MIT, ele pediu demissão desse centro de pesquisa e passou a dedicar-se totalmente a duas iniciativas: o projeto GNU (criado em 1984) e, um ano depois, a Free Software Foundation. Essas iniciativas ganharam domínio público a partir do desenvolvimento do sistema operacional GNU/Linux.

Braga, 2007, discute mais pontualmente essa questão, refletindo sobre a forma como essa iniciativa de produção aberta e colaborativa, inicialmente motivada por princípios de natureza anárquica, foi posteriormente apropriada pela indústria de software para atender aos interesses comerciais de uma segunda iniciativa - "Open Source" ou código aberto. Iniciado em 1998, esse segundo movimento ganhou maior popularidade a partir de um artigo publicado por Raymond, 2000, intitulado "A catedral e o bazar". Em linhas gerais, esse novo movimento salienta a possibilidade de integrar as diferentes habilidades das comunidades técnicas para construir produtos de uma forma mais dinâmica e qualitativamente diferenciada, já que os softwares criados podem ser testados durante o processo de seu desenvolvimento, não necessitando mais ser disponibilizados após testes fechados nas empresas. Essa nova orientação ampliou a participação dos técnicos no mercado de produção e venda de software, mas não alterou de forma radical a noção de participação coletiva no consumo do conhecimento técnico coletivamente produzido, defendida pelo movimento do Software Livre.

No presente estudo essas duas orientações ideológicas são apresentadas de forma sintética com o intuito de contextualizar um debate existente na área técnica, que motivou um conjunto de três entrevistas discutas em Braga, 2007. Nessas entrevistas a posição de três jovens produtores de software foram investigadas: um jovem universitário, reconhecido como grande defensor do movimento do código aberto e dois jovens técnicos, um universitário e o outro um líder comunitário, ambos engajados no movimento de software livre. A discussão que segue explora de forma mais detalhada os dados coletados na entrevista feita com a liderança local. A análise a ser apresentada teve como meta ilustrar modos de apropriação da tecnologia pelas comunidades carentes e a visão do líder entrevistado sobre o espaço aberto na Internet para produção de consumo de bens culturais.

\section{PARTICIPAÇÃO E APROPRIAÇÃO DE BENS CULTURAIS: REFLEXÕES DE UMA LIDERANÇA LOCAL SOBRE SUA RELAÇÃO COM AS TICS E ENGAJAMENTO NO MOVIMENTO DO SOFTWARE LIVRE}

\subsection{Contextualizando a entrevista}

A cidade de Campinas possui um conjunto de iniciativas locais que eventualmente estabelecem parceria com os pesquisadores da Unicamp, seja para fornecer bolsas de 
pesquisa para alunos envolvidos em atividades de cunho social, seja para desenvolver projetos de pesquisa concebidos pela universidade ou em iniciativas conjuntas de ação social que envolvem membros dos movimentos comunitários e da universidade. O contato inicial da pesquisadora com uma dessas iniciativas gerou o interesse em desenvolver atividades práticas em uma disciplina regular de graduação, cujo conteúdo programático é centrado em discussões introdutórias sobre o letramento digital. O objetivo principal das novas atividades pedagógicas propostas era criar uma maior sensibilização dos universitários com as diferenças sociais que constituem a realidade urbana da cidade de Campinas. O primeiro passo foi apresentá-lo, de forma explícita, às lideranças de um Centro Cultural localizado na periferia da cidade de Campinas.

A escolha do Centro Cultural em questão foi motivada por duas razões. Ele tinha se tornado - ao longo de um trabalho de mais de uma década - um Centro de referência em nível nacional e internacional; além disso, sua atuação destacava-se em duas grandes frentes: preservação da tradição cultural afro, que marca a descendência da maior parte dos membros da comunidade local, e ações no sentido de ampliar o acesso comunitário às TICs. Essa última iniciativa tinha sido tão bem sucedida que vários dos jovens acolhidos no Centro já se destacavam pela qualidade de seu conhecimento técnico e participação ativa nas comunidades técnicas virtuais - alguns deles chegaram a ser chamados para participar na implantação de tecnologia realizada por projetos oficiais em áreas remotas da região norte brasileira (um ponto que gerava certos conflitos entre as lideranças da Casa de Cultura na época em que a experiência pedagógica foi realizada).

Em relação à disciplina esperava-se estabelecer uma relação dialética entre teoria e prática. Esperava-se que no final do semestre os alunos construíssem sites norteados pelas leituras realizadas e de acordo com duas direções: uma voltada para a integração de perspectivas de áreas distintas (cursos de Letras e Midialogia), e a outra voltada para questões de diferenças sociais. Essa última previa a criação de dois sites voltados para divulgação de atividades desenvolvidas na comunidade contatada. ${ }^{1}$ Para essa última atividade, ficou estabelecido que o contato entre os membros da comunidade e da universidade ocorreriam de duas formas: visitas dos alunos ao Centro Cultural e a um cursinho pré-vestibular que também era conduzido como uma iniciativa local no mesmo bairro; e visita das lideranças comunitárias à sala de aula na UNICAMP. Esses encontros foram explorados para discutir questões relativas às atividades práticas propostas.

A experiência aqui relatada ocorreu em 2005 e prolongou-se pelo período de um semestre letivo. Essa experiência despertou na professora/pesquisadora um interesse particular em entender as questões relativas ao movimento do software livre. Essa curiosidade foi gerada pelo fato de ter sido esse um dos problemas mais sérios enfrentados pelos estudantes universitários nessa interação. Mais especificamente, os alunos da UNICAMP (cursos de Letras e de Midialogia) estavam familiarizados com os recursos oferecidos pelos softwares comerciais a que tinham acesso, e tiveram muita dificuldade em migrar esse conhecimento para os softwares livres adotados no Centro Cultural. Essa mudança de orientação, na realidade, colocou os membros da comunidade na posição de liderança na discussão de questões técnicas, e esse desequilíbrio em relação ao conhecimento de prestígio foi importante para motivar um conjunto de reflexões críticas de cunho social.

\footnotetext{
${ }^{1}$ Para mais detalhes ver Braga, 2007a e 2007b.
} 
BRAGA - Tecnologia e participação social no processo de produção...

A entrevista analisada no presente estudo foi gravada em áudio seis meses após ter sido concluída a disciplina. A gravação foi realizada no Centro Cultural pela pesquisadora, e o líder comunitário escolhido concordou em participar após ser informado de que os dados obtidos visavam refletir sobre o debate existente entre as três grandes tendências de geração de conhecimento técnico: software proprietário, open source e software livre. Foi também explicitado que esses dados iriam ser comparados com os dados obtidos por dois estudantes universitários da área técnica, um deles militante do movimento do software livre e o outro grande defensor das diretrizes propostas pelo movimento em defesa do código aberto. Foi também esclarecido que o estudo em curso estava vinculado a duas preocupações da pesquisadora: entender formas novas de explorar as novas tecnologias em práticas educativas, e formas alternativas de ampliar o acesso e a participação social das comunidades periféricas, explorando os recursos oferecidos pelas TICs.

Para fins da presente discussão, a entrevista do líder comunitário é analisada isoladamente, de modo a permitir um maior destaque a três pontos bastante evidenciados durante essa entrevista: acesso às inovações tecnológicas por meio de contatos iniciais de natureza mais coletiva, apropriação crítica das TICs e novos espaços para a participação social dos grupos economicamente desfavorecidos. Quando necessário, esses dados são complementados com dados de um segundo entrevistado que participou espontaneamente dos primeiros 20 minutos da entrevista realizada.

\subsection{Tecnologia e participação social: o que podemos aprender com as experiências e avaliações de uma liderança local}

\subsubsection{Apropriação dos letramentos digitais}

Resgatando o percurso pessoal de apropriação da tecnologia digital narrado pelo entrevistado é possível identificar a migração de saberes adquiridos dentro de práticas letradas específicas para novos contextos de uso e as adaptações desses saberes a esses novos usos. Mostra também que o contato com letramentos digitais dos grupos periféricos pode ser realizado através de um conjunto de experiências e experimentações distintas, muitas delas propiciadas por trocas dentro da própria comunidade. Relembrando seu primeiro contato com as TICs, o primeiro entrevistado (E) relata:

\footnotetext{
E3: [idade do contato] uns 7, 8 anos. Aí uma pessoa tinha um vídeo game, que era um vídeo game que foi lançado da Philips, eu acho. Chamava Odyssey. E esse vídeo game ele tinha um teclado embutido no console dele, que era um teclado daqueles bem tosquinhos mesmo e que permitia que você fizesse seus jogos ali. Então esse foi o meu primeiro contato com o computador, antes mesmo de ter a idéia da noção de computador e tal.
}

Seu depoimento indica que uma apropriação da tecnologia pode ser feita pelas crianças de uma forma bastante sofisticada através da experimentação em atividades lúdicas. Nessas atividades o domínio técnico é adquirido com base na inferência construída a partir de um conjunto de pistas, que podem tanto ser as respostas dadas pelo sistema, quanto informações parciais oferecidas pelos manuais. No exemplo dado, o manual era escrito em língua estrangeira que as crianças não dominavam, mas o fato de ter sido mencionado durante a entrevista pode levar a supor que tenha oferecido informações visuais (desenhos, 
por exemplo) que foram também exploradas pelas crianças para construir conhecimento sobre o funcionamento do jogo em questão.

E4: Como eu aprendi de pequenininho? (...) Foi usando. A gente via... jogava muito vídeo game e esse computador ele vinha com um manual que na verdade era um manual em alemão que ensinava você a criar alguns jogos e tal. E a gente não entendia alemão, mas a gente entendia a base de comandos que eu acho que programava em Lotus Notes, sei lá, programava numa linguagem lá, específica pra esse console, pra esse Odyssey e a gente aprendeu por ali. A gente sabia que entrando... aprendeu o que eram as entradas o que eram os "zoos e sis". E todo esse tipo de coisa a gente aprendeu ali fazendo mesmo. Eu aprendi a programar nesses consoles, na mesma época que eu aprendi a ler mais ou menos. Então foi uma coisa que veio junto.

Esse conhecimento, adquirido de forma lúdica e exploratória serviu posteriormente de base para o desenvolvimento de práticas altamente especializadas na área técnica, como construção de programas, um dado que indica a importância de os indivíduos serem expostos e terem acesso a tecnologia em diferentes atividades de seu cotidiano.

E5: Quando eu comecei a programar foi com uns 8 assim. Mas eu parei muito tempo de programar, mas essa abertura que eu tive pra poder utilizar esse primeiro console que me valeu depois... a facilidade que eu tenho hoje de manusear qualquer tipo de software e sistema operacional veio daí. A gente entendeu muito da base da coisa assim.

Oportunidades de acesso - como era de se esperar - também foram fundamentais para que o domínio da tecnologia ocorresse. Mesmo quando tais contatos não atingem as metas originalmente propostas, eles permitem que os indivíduos se apropriem de conhecimentos que podem ser úteis em usos futuros, como ocorreu com essa liderança entrevistada nas suas vivências posteriores.

E3: (...) a primeira vez que eu tive contato com o computador, inclusive, foi por intermédio da universidade, com o Personal Computer, foi por intermédio da UNICAMP com um projeto que se chamava "Rede dos Pesquisadores Marxistas" em que eu pude editar uma revista pra rede.

Os depoimentos do entrevistado $(\mathrm{R})$ - também membro da comunidade e que esteve presente nos primeiros 20 minutos da entrevista - mostram que, mesmo sem um contato direto com as TICs, todas as camadas da população já estavam de forma direta ou indireta expostas à tecnologia digital, mesmo antes da popularização de seu uso ou da expansão da telefonia celular, que hoje está mais acessível às camadas de baixa renda da população.

R1: A primeira vez que eu vi um computador é até engraçado, foi num desenho animado da família Jackson. E depois a outra vez foi no programa do Balão Mágico que eles tinha lá aquela formatação deles dentro lá do disco voador com o Raul Seixas Pluct-Plact-Zum. Mas fisicamente, o computador real, não o computador de desenho, eu vi quando eu tinha em torno de uns doze anos. Tinha um amigo meu que era guardinha e trabalhava na prefeitura e usava aqueles computadores super enorme com aqueles disquetão enorme assim. 
BRAGA - Tecnologia e participação social no processo de produção...

A experiência de circulação em esferas sociais fora do âmbito comunitário permitiram a (R) não só a observação de algumas práticas letradas digitais, mas também um aprendizado que ocorreu de modo informal, pela experimentação e pela imitação. O uso de recursos oferecidos pelo meio em práticas digitais específicas permite inferir e adquirir de forma não analisada a lógica que organiza os programas. Demandas de práticas cotidianas - produzir cartazes, escrever textos, usar planilhas - acabam expandindo o escopo dos letramentos iniciais, como ilustra o depoimento que segue.

\begin{abstract}
R1: Mas pegar, mexer [no computador] mesmo foi quando eu já 'tava com uns dezesseis, dezessete anos que eu vi um amigo meu... eu fazia assessoria política no DCE da PUC (...) ele 'tava lá num computador e ficava lá num tal de bate-papo e eu olhava assim e achava interessante ... Daí tinha um menino que ficava zipando tudo e eu falei assim: "Como que funciona isso?" Daí ele falou assim: "Assim". Daí ele me colocou lá na frente do computador, dai eu comecei a mexer, dai comecei entender a Internet e algumas coisas assim, mas não aprofundar em teorias. Tudo que eu observava eu aprendia, copiava assim (...) Daí depois fui vendo, participando, usando ele pro dia-a-dia, pra questão funcional, pra fazer cartazes, de um jeito meio tosco, então pra fazer texto, fazer planilha. Depois também eu 'tava trabalhando como tesoureiro tinha que usar o Excel. Daí depois fui aprendendo e cheguei aqui na Casa de Cultura (...)
\end{abstract}

Esses relatos retomam uma realidade do início dos anos '90, quando a tecnologia ainda não estava acessível nas lan houses, nos centros comunitários, acoplada a telefones celulares ou mesmo aos computadores pessoais, hoje mais acessíveis para comunidades periféricas. Os resultados obtidos a partir de um acesso bastante limitado e restrito permitemnos conjecturar que as experiências atuais, sendo mais diversas e complexas, tornam possível uma apropriação da tecnologia de forma bem mais dinâmica do que costumávamos acreditar.

As entrevistas também apontam formas criativas através das quais esses jovens buscam socializar o conhecimento sobre a tecnologia ou refletir sobre o potencial dos ambientes que ela oferece. Notam-se tentativas de usar as linguagens das novas mídias na busca de ensinar o uso dessas mídias. Esse é o caso de (R), que tem uma predileção marcada por desenho, e que contempla a possibilidade de usar esse recurso expressivo para ensinar o uso do computador:

R3: (...) Então tinha colocado uma proposta que eu tenho dificuldade de entender como eles (jovens que frequentam o Centro Cultural) entendem a vivência diferenciada, o contato com o computador. Tinha pensado na possibilidade de fazer essa molecada entender o computador através do desenho animado ou em história em quadrinho, mas tem uma produção daí precisa juntar o pessoal aí fazer um gibizinho. Eu acho fascinante o computador.

O depoimento de (E), que segue, ilustra o fato de que a fronteira entre o virtual e o real é bastante imprecisa, quando se trata de comunidades virtuais.

E19: Tem um menino ai que 'tava falando uma coisa que eu achei legal, tipo assim quando você trabalha, por exemplo, com um com o Orkut você veste uma representação. $\mathrm{Na}$ verdade a gente é vestido disso mesmo. Eu sou eu, mas eu sou o [X] lá em casa pra minha mãe pro meu pai que depois as pessoas foram abrigando lá as minhas personificações dentro disso. E é um caso do Orkut lá, você vestiu uma personificação e quando você 
trabalha dentro de uma comunidade de software livre, apesar também de você poder se vestir disso, eu sou o [X da Casa de Cultura], por exemplo, que é minha outra personalidade dentro de um universo ai livre e tal. Mas ali, realmente, eu 'tô muito mais como eu, do que eu não 'tô. Eu 'tô me relacionando virtualmente, mas eu tenho na minha comunidade uma responsabilidade que é concreta, de discutir, debater e de construir coisas. Ele [software livre] proporciona muito mais uma construção dentro do seu ciclo de relações reais ou virtuais, não sei, mas concretas, ele proporciona muito mais isso.

\subsubsection{Internet e participação nos processos de produção e consumo de bens culturais: o que temos a aprender com a voz da liderança local}

Embora a discussão sobre o acesso à tecnologia tenha sido em grande parte vinculada a noções de "inclusão social" - na maioria das vezes entendida como "ampliação do acesso ao mercado de trabalho" -, fica claro, nas colocações do entrevistado, que não é essa a percepção nem são essas as metas estabelecidas por certas lideranças locais. Os trechos da entrevista que seguem ilustram bem a percepção desse jovem líder; a percepção de que o espaço de participação reservado para seu grupo social é o de uma inclusão na periferia técnica do processo de expansão da tecnologia de comunicação. Nas emissões de numero 6 e 7 o entrevistado discute sua formação escolar. Relata que fez toda a sua formação até o segundo grau na mesma escola pública, localizada na periferia de Campinas. Após a conclusão do segundo grau, a falta de perspectiva de trabalho levou-o a tentar um curso técnico de mecânico industrial no Senai. Segundo seu depoimento, foi no SENAI que começou a refletir sobre a indústria do software e sobre o movimento sindical:

E6 : ... [completei] o segundo grau numa escola (...) lá da periferia do São Fernando. E quando eu saí de lá eu fiquei meio perdidão e fui fazer SENAI. (...) fiz um curso de mecânico, mecânico industrial. Lá na mecânica industrial eu tive contato com um processo de automação, entendi... lá eu comecei a entender um pouco do que era indústria de software pra produção em massa e esse tipo de coisa, dentro do SENAI. E lá também que eu conheci a possibilidade do sindicato e da luta social... foi dentro do SENAI.

Após a conclusão desse curso técnico, ainda no início dos anos 1990, a situação de desemprego que já atingia o país levou-o a procurar uma formação em outra área técnica:

E7: (...) Quando eu saí do SENAI eu saí mais perdido ainda, assim, de perspectivas de futuro (...) já era uma época de total desestabilização do trabalho formal. O próprio sindicato, os contatos que a gente tinha já mostravam isso, já mostravam o desemprego, e a dificuldade que a gente teria tendo aquela formação de operador de máquina. E aí eu fui fazer um outro curso no SENAI pra saber: "Meu!!! qual que é agora o emprego do futuro? eu preciso trabalhar porque senão eu vou morrer". Aí eu fui fazer um curso de tecnologia de comunicação (...) e de processamento de dados industrial também, de lógica de processadores, na verdade.

É interessante ressaltar que nesse processo de formação para o trabalho ele se dá conta de como o discurso da "inclusão" e da "oportunidade de trabalho" na realidade mascarava a exclusão de uma participação mais significativa no processo de mudança social que estava ocorrendo: 
BRAGA - Tecnologia e participação social no processo de produção...

E7: E de novo eu acabei entrando num ciclo que me fez entender qual era o grande negócio aqui da América Latina de comunicação, porque na verdade a gente 'tava sendo formado pra ser os técnicos que fizeram toda essa articulação de rede interna, cabeamentos de fibra ótica, cabo de dados. (...) Mas é isso, era cavar buraco e executar mega projetos de comunicação assim. Então a gente 'tava sendo formado pra isso. Tanto que falavam: "Não, porque agora vocês têm um mercado de trabalho. É um mega mercado de trabalho das telecomunicações”.

Tal constatação gera uma posição de resistência ao lugar social pré-estabelecido e a busca de outras alternativas profissionais:

E7: Esse curso eu não terminei, porque eu já não tive mais desejo assim, me sentia meio enojado mesmo pela coisa. (...) Essa falta de visão da tecnologia de comunicação como uma ferramenta de mudança social, o que as comunidades pudessem se apropriar daquilo de uma forma ou não não consumista, não consumidoras de uma tecnologia pra poderem fazer um papel de usuários dos serviços dos mega corps e tal Eu acabei saindo e me afastei até dessa área da tecnologia por achar que ela era muito... uma área que eu não ia conseguir me livrar dessa interferência dos mega-oligopólios de comunicação. Ou eu ia trabalhar pra eles ou então eu não ia fazer nada. (...) Isso foi um dos motivos que me levou a abandonar geral a tecnologia, abandonei bastante tempo e fui trabalhar com música. Minha formação básica é essa. E depois a formação que eu considero mais importante é a formação aqui na Casa de Cultura (...)

O percurso realizado por essa liderança local indica um olhar bastante crítico dirigido ao processo social mais amplo envolvendo tecnologia, nem sempre evidente ou explicitado por aqueles que discutem o acesso a essa tecnologia e os benefícios previstos para os assim chamados "excluídos digitais". Sua fala também aponta para possibilidades mais progressistas de reflexão e apropriação dos avanços técnicos trazido pelas TICs, avanços esses que subvertem as diretrizes previstas pelos grandes centros geradores de tecnologia:

E 13: A Internet ela já é um meio livre. As primeiras discussões que a gente teve quando a gente começou a trabalhar com educação na rede foi assim: "O que é a rede? $O$ que é, primeiro, a Internet? Histórico da Internet”. Essa busca da gente de entender a Internet e depois de compreender o que era a Web, a gente começou a fazer esse paralelo da rede institucional que a Internet é, a rede dos grandes negócios e dos grandes portais, dos grandes comandantes da comunicação, que é a Internet. E a web que seria a rede mesmo, que seria essa rede subversiva, de relações sociais que se constroem não só com esse intuito de dominação econômica.

$\boldsymbol{E}$ 14: [uma ferramenta pode ser] subversiva no sentido de não se render totalmente à grande chamada da tecnologia, que é o domínio ideológico, domínio estrutural e domínio econômico das macro-regiões. Eles pensam isso no sentido de macro-regiões das Américas, da África. E agora tem um plano todo pra África de fibra ótica, um troço maluco assim. Então de você não se vender a isso, num primeiro sentido e de criar um diálogo entre comunidades que esteja voltado ao desenvolvimento, um desenvolvimento que seja sustentável dessas comunidades. Porque a gente sente que é insustentável você aderir, por exemplo, ao plano da Microsoft de inclusão digital. É impossível.

Esses questionamentos sobre compromisso social de certas iniciativas privadas ficam bastante evidentes quando, em um trecho da entrevista, o líder comunitário fala de uma experiência concreta na qual uma grande empresa compartilha com a sua comunidade a 
sucata técnica já descartada pelas camadas mais favorecidas da sociedade. Esse depoimento também é interessante para ilustrar que os grupos economicamente desfavorecidos não são pacíficos frente à distribuição desigual de bens culturais. Em movimentos de tática, no sentido proposto por Certeau (1994), o depoimento ilustra como eles aproveitam a ocasião, operam golpe a golpe aproveitando as falhas de vigilância dos grupos que detêm o poder, num movimento de reapropriação do lugar do poder e do querer considerados legítimos e "próprios", a favor do fraco, como caminhos ou modalidades de inclusão. Como observa Buzato, a tática é arte do fraco que se realiza no espaço do forte, "a ação calculada que é determinada pela ausência de um próprio (Buzato, 2007, p.51).

E12 (...) a gente tinha problemas com proteção, com licença. A casa na história toda dela
de uso de software proprietário, uns seis anos de software proprietário, a gente nunca pagou
uma licença de software. Teve um momento que a gente recebeu um apoio da Macromídia
... que a Macromídia doou algumas licenças de software pra gente, mas eram muito ruins
e a gente continuou usando os piratas, que era mais legal, os piratas tinham mais aplicativos
e tal. E a gente ganhou duas caixas lá de software da Macromídia, mas a gente continuou
pirateando eles.

É interessante que o termo "pirataria", nesse caso, refere-se não ao ato de se apropriar de um bem usado por outro, mas sim de participar das possibilidades de uso desses bens. Os membros da comunidade ganharam caixas de programas, mas tinham interesse em usar os aplicativos das versões mais recentes, comercializados para as camadas mais abastadas da população. O movimento do software livre provoca uma alteração no processo de apropriação.

$\boldsymbol{E} 18$ [com o] software proprietário você pode se comunicar com pessoas que vivem num mesmo circuito de consumo que você. Ou elas consomem aquilo ou de uma certa forma elas roubam aquilo, porque se você utilizar um software sem licença você 'tá roubando, legalmente você 'tá roubando aquilo. [o software livre] permite que você viva um ciclo de experiências muito diferentes que visam outro tipo de integração.

Nota-se, nos relatos feitos durante a entrevista, uma passagem radical do papel de consumidores de um conhecimento produzido pelos grupos hegemônicos para produtores desse conhecimento. Esse movimento de mudança, no entanto, parece estar diretamente atrelado à possibilidade de trocas mais amplas que extrapolam as discussões mais fechadas dos grupos comunitários. Nesse sentido a Internet trouxe mesmo um espaço diferenciado de participação.

$\boldsymbol{E} 12$ (...) A gente começou a entender o princípio de software livre, pelo menos eu comecei a entender através da construção de redes, dessas redes virtuais, vamos dizer assim, dessas redes através da Internet. Então a partir daí eu comecei a entender o que era a possibilidade de você utilizar essa tecnologia construída coletivamente, de colaborar com a construção de tecnologias pra poder proporcionar uma transformação numa forma de ver a própria questão da tecnologia e as relações comunitárias. Então a gente começou a trabalhar e isso porque também a gente não tinha [antes desse momento] acesso a essa discussão proprietário, livre porque a gente não tinha acesso a Internet. Isso é muito importante de salientar porque a gente passou muito tempo trabalhando aqui sem ter acesso a web. 
É interessante ver como o discurso sobre liberdade de acesso ao conhecimento que foi ideologia propulsora do movimento do software livre foi incorporado às reflexões comunitárias sobre a produção de bens culturais. Os trechos que seguem ilustram bem esse discurso, que fica mais evidente na maneira como o entrevistado responde ao pedido de esclarecimento da pesquisadora no trecho (E18). Sua fala deixa evidente que a questão central da discussão não é "compartilhar" um conhecimento criado de uma forma mais democrática, mas sim salientar que todo o conhecimento é gerado com base em conhecimentos e experiências culturais prévias e, portanto, o acesso a esse conhecimento é direito de todos.

E16 As pessoas sempre colocam isso assim: "Você tem que ter o acesso ao computador pra você poder ter um emprego, pra você poder subir na vida". Esse lance de subir na vida, que é muito louco e tal. O software livre ele quebra isso, ele permite que você discuta o seguinte: "O que é o conhecimento? O que é o conhecimento que constrói tudo, vamos dizer assim, que constrói as coisas materiais, físicas e tal, e que constrói essa ferramenta que você utiliza pra mandar e-mail, por exemplo. Isso é um conhecimento matemático? E a quem pertence esse conhecimento matemático? Quem é o dono do Teorema de Pitágoras? O Pitágoras? Tem que pagar alguma coisa? Quem são os remanescentes do Pitágoras? O software livre, ele permite discutir isso, cara, que 'o conhecimento, na verdade todo conhecimento que foi abduzido pela academia (...) na verdade ele é um conhecimento das comunidades, que ele é ancestral e ele é uma forma de compreender a natureza, a natureza humana e a natureza dessa relação do ser humano com a natureza. (...) O software livre permite isso, permite entender que todas as ferramentas, inclusive aquelas que são utilizadas para domínio das culturas e as linguagens são construídas a partir de conhecimentos tradicionais.

Pesquisadora: (...) quando você fala em software livre, pra você, "livre”, tem a ver com essa questão do conhecimento que deveria ser de todo mundo? É isso?

E18: Não. Do conhecimento que é de todo mundo. É difícil... às vezes as pessoas não conseguem acreditar que uma coisa que vem muito delas mesmas pode ser responsável pela construção de um equipamento $X$ ou de um equipamento $Y$ e por isso a gente fez, por exemplo, uma experiência com o Corel Draw. Como que eles entendem a construção daquelas ferramentas que depois de construídas você não pode mais alterar nem compartilhar, nem nada. Mas como que foi compreendido, por exemplo, o uso de um pincel? O pincel é uma coisa humana de você catar um troço e melecar num bagulho e esfregar num outro bagulho, entendeu? E daí essa é uma tecnologia da mais livre possível, qualquer criança de seis meses cata um troço, meleca num troço e esfrega na parede, entendeu? E dizer pras pessoas: "Olha essa tecnologia pertence a todos nós, então por que nós não podemos usar ela da melhor forma possível e compartilhar ela com o maior número de pessoas possível? Então essa questão do software (livre), pra mim (...). Ele é uma forma de você trabalhar o resgate desse conhecimento ancestral.

Essas reflexões a respeito do direito coletivo sobre os bens culturais produzidos na sociedade foi de forma direta ou indireta instigado pela própria tecnologia que, em última instância, foi criada para atingir objetivos sociais muito distintos, relacionados a novas formas de concentração de renda e formas de realizar negócios.

$\boldsymbol{E}$ 19: [software livre] Ele permite que você crie outros ambientes de relação, vamos dizer assim, que não tão vinculados a essas organizações econômicas, não têm essa visão de ascensão social individualista. Então essa coisa de ele ser construído colaborativamente, 
através de comunidades É uma coisa muito interessante isso como a gente trabalha ali estudando com os meninos, tipo, o que é construir um software livre hoje? Como que você se inscreve dentro de uma comunidade? Quais são as intenções dessa comunidade?

E 12: A gente começou a entender o princípio de software livre, pelo menos eu comecei a entender através da construção de redes, dessas redes virtuais, vamos dizer assim, dessas redes através da Internet. Então a partir daí eu comecei a entender o que era a possibilidade de você utilizar essa tecnologia construída coletivamente, de colaborar com a construção de tecnologias pra poder proporcionar uma transformação numa forma de ver a própria questão da tecnologia e as relações comunitárias.

\section{CONSIDERAÇÕES FINAIS}

Retomando as questões iniciais, o processo de estruturação social, como ressalta o estudo de Jessop (1985) envolve três elementos: a comunicação de sentido, o exercício do poder e o julgamento qualitativo da conduta; todos eles historicamente barreiras à participação nos processos de produção e consumo de bens culturais (principalmente aqueles que circulam nas esferas de mais poder e prestígio social) sempre favoreceram os grupos hegemônicos. Ou seja, o isolamento imposto aos grupos periféricos dificulta a percepção de alternativas e de escolhas pressupostas em leituras sociais críticas. Os estudos iniciais sobre as práticas letradas mostraram tanto a diversidade dos padrões linguísticos e letrados adotados por diferentes grupos sociais, quanto ofereceram subsídios para refletirmos sobre o fato de que, embora todas as diferenças se justifiquem dada a diversidade que constitui a cultura mais ampla, nas situações de conflitos, quando há uma assimetria nas relações de poder, espera-se que seja justamente o grupo mais desfavorecido o que construa as pontes, adquira novos padrões linguísticos e sociais, dentro de exposições altamente precárias, como são aquelas oferecidas pelas práticas escolares.

A Internet mudou essa relação de diferentes maneiras, permitindo novos acessos e modos de participação em processos de consumo de bens culturais e, como indicou a voz da liderança local entrevistada, de participação e apropriação local do conhecimento. A análise priorizou a produção coletiva de software, um exemplo relevante, na medida em que se trata de produção de um tipo de saber hegemônico que é central ao processo atual de globalização do mercado e da cultura. Não perdendo de vista que a análise considerou apenas o relato de uma experiência pessoal de um jovem altamente preparado em termos técnicos e politicamente engajado, seus argumentos indicam o potencial de apropriações locais da tecnologia que podem favorecer e fortalecer movimentos de contra-discurso. Pode-se dizer, pois, que as TICs não mudam os modos de participação social, mas potencializam novas alternativas. Como pondera Braga, "a direção do desenvolvimento tecnológico e das mudanças sociais dele advindas está sempre ligada a valores e ideologias pré-existentes que podem também mudar em novas direções quando a adoção dessa tecnologia transforma a própria natureza das práticas sociais pré-existentes" (Braga, 2007c:80).

As reflexões tecidas ao longo da entrevista pelo líder comunitário oferecem algumas interpretações que nos provocam a pensar nessa direção. Elas também levantam um problema para nós acadêmicos em relação à propriedade intelectual, que é central ao nosso modo de 
construção de conhecimento no campo profissional. Em última instância, a busca de entender o outro obriga-nos a fazer uma reflexão mais séria sobre nós mesmos. Para defender posturas mais igualitárias e participativas no plano político, somos obrigados a rever as barreiras que construímos em defesa de nosso lugar de poder. Esse não é um processo simples. Ele gera um conjunto de conflitos reais que não podem ser menosprezados quando migramos da teoria para a práxis social. Mas não é viável defendermos estruturações sociais alternativas, excluindo-se a necessidade de novos arranjos nos espaços de participação de $\underline{\text { todos }}$ os grupos sociais constitutivos da sociedade mais ampla, inclusive o nosso.

Concluo o texto retomando a voz do entrevistado que foi o interlocutor central da pesquisadora nesse processo de reflexão. Em termos de participação social, os recursos de interação oferecidos pelas TICs, em geral, e pela Internet, em particular, apontam para " $a$ possibilidade de (...) utilizar essa tecnologia construída coletivamente (...) pra poder proporcionar uma transformação, numa forma de ver a própria questão da tecnologia e as relações comunitárias.” (...) "essa tecnologia pertence a todos nós, então porque nós não podemos usar ela da melhor forma possível e compartilhar ela com o maior número de pessoas possível?” Eis aí, em poucas e lúcidas palavras, o grande desafio lançado aos educadores engajados em ampliar o acesso às práticas letradas digitais. É preciso urgência em acolhê-lo.

\section{REFERÊNCIAS BIBLIOGRÁFICAS}

BAUMAN, Z. (2001). Moderidade Línquida. Rio de Janeiro: Jorge Zahar.

(2003). Comunidade: A busca por segurança no mundo atual. Rio de Janeiro: Jorge Zahar.

BRAGA, D. B. (2007a). Developing Critical Social Awareness Through Digital Literacy Practices Within the Context of Higher Education in Brazil. Language and Education a, v. 21, p. 180-196.

(2007b). Práticas letradas digitais: considerações sobre possibilidades de ensino e reflexão social Crítica. In: Júlio César Araújo. (Org.). Internet \& Ensino - Novos gêneros, outros desafios. Rio de Janeiro: Lucerna, v. 1, p. 181-195.

(2007c). Social interpretations and the uses of technology: A Gramscian explanation of the ideological differences that inform programmers positions. Critical Literacy in Global Citizenship Education, v. 1, p. 80-89.

BUZATO M. E. K. (2007). Entre a fronteira e a periferia: linguagem e letramento na inclusão digital. Tese de doutoramento, IEL, UNICAMP.

(2008). Inclusão digital como invenção do cotidiano: um estudo de caso. Revista Brasileira de Educação, v.13, n.38, p.325-413.

CERTEAU, M. (1994). Invenção do cotidiano: artes do fazer. Tradução Ephrain Ferreira Alves Petrópolis: Vozes.

GEE, J. (1991). Social Linguistics: Ideology in Discourses, London: Falmer Press.

GIDDENS, A. (1987). Social Theory and Modern Sociology. Cambridge: Polity Press.

GNERRE, M. (1991). Linguagem escrita e poder . São Paulo: Martins Fonte.

GRAMSCI, A. (1971). In: Q. Hoare \& Nowell-Smith (Eds.) Selection from the Prison Notebooks London: Lawrence \& Wishart. 
JESSOP, B. (1989). Capitalism, nation-states and surveillance. Em: Held, D e Thompson J.B. Social Theory and Modern Societies : Anthony Giddens and his critics. Grã-Bretanha: Cambridge University Press.

HEATH, S. B. (1983). Ways with Words: Language, life and work in communities and classrooms. Nova Iorque: Cambridge University Press.

MICHAELS, S. E COLLINS M. (1984). Oral Discourse Styles: Classroom interaction and the acquisition of literacy. Em: Tannen, D (eds) Coherence in Spoken and Written Discourse. Norwood, New Jersey: Ablex Publishng Corporation, p. 219-244.

GUMPERZ, J. J. (1977). Sociocultural knowledge in conversational inference. Em: Saville-Troike, M. (eds) Georgetown Round Table on Language and Linguistics. Washington: Linguistics and Anthropology.

POYNDER, E.S. (2006). http://poynder.blogspot.com/2006/03/interview-with-richard-stallman.html. Consultado em 2/2/2007.

RAYMOND E.S. (2000). The Cathedral and the Bazaar http://www.catb.org esr/writings/cathedral-bazaar/ cathedar-bazaar. Consultado em 30/01/ 2007.

Recebido: $25 / 07 / 2010$

Aceito: 30/11/2010 
